\title{
Pengaruh Masa Kerja dan Profesionalitas Guru terhadap High Order Thinking Skill Siswa SMK melalui Level Soal Ujian
}

\author{
Elfia Najib Kholifiatin ${ }^{1}$, Eddy Sutadji ${ }^{2}$, Syaad Patmanthara ${ }^{3}$ \\ ${ }^{1}$ Pendidikan Kejuruan-Universitas Negeri Malang \\ ${ }^{2}$ Teknik Mesin-Universitas Negeri Malang \\ ${ }^{3}$ Teknik Elektro-Universitas Negeri Malang
}

\begin{tabular}{|c|c|}
\hline INFO ARTIKEL & \multirow{6}{*}{$\begin{array}{l}\text { ABSTRAK } \\
\text { Abstract: Many teachers in making exam questions do not pay attention to the level of } \\
\text { cognitive realm that is High Order Thingking Skill to achieve quality graduates so that } \\
\text { they have not been able to improve students' thinking skills. The purpose of the study } \\
\text { was to describe the influence of teacher personality demographics and professionalism } \\
\text { on students' level of thinking with the type of exam questions made by the teacher. This } \\
\text { research is a type of ex post facto research that is descriptive and inferential. Data } \\
\text { analysis techniques in this study used descriptive analysis and Path Analysis. The result } \\
\text { of data analysis showed that Vocational High School's students have low thinking level. } \\
\text { Students' thinking ability is influenced by the types of questions created by the teacher. }\end{array}$} \\
\hline Riwayat Artikel: & \\
\hline 2019 & \\
\hline Disetujui & \\
\hline Kata kunci: & \\
\hline $\begin{array}{l}\text { teacher professionalism; } \\
\text { high order thinking skill; } \\
\text { level exam questions; }\end{array}$ & \\
\hline
\end{tabular}

profesionalitas guru;

high order thinking skill;

level soal ujian

\begin{abstract}
Abstrak: Banyak guru dalam membuat soal ujian belum memperhatikan tingkat ranah kognitif High Order Thingking Skill untuk mencapai lulusan yang berkualitas sehingga belum dapat meningkatkan kemampuan berpikir pada siswa. Tujuan penelitian ini untuk mendeskripsikan pengaruh demografi personality dan profesionalitas guru terhadap tingkat berpikir siswa dengan jenis soal ujian yang dibuat oleh guru. Penelitian in merupakan jenis penelitian ex post facto yang bersifat diskriptif dan inferensial. Teknik analisis data dalam penelitian ini menggunakan analisis diskriptif dan Path Analysis. Hasil analisis data menunjukkan bahwa siswa SMK memiliki tingkat berpikir rendah. Kemampuan berpikir siswa dipengaruhi oleh jenis soal yang dibuat oleh guru.
\end{abstract}

\author{
Alamat Korespondensi: \\ Elfia Najib Kholifiatin \\ Pendidikan Kejuruan \\ Universitas Negeri Malang \\ Jalan Semarang 5 Malang \\ E-mail: elfianajib@gmail.com
}

Pendidikan adalah usaha sadar dan terencana untuk mewujudkan suasana belajar dan proses pembelajaran agar peserta didik secara aktif mengembangkan potensi dirinya, salah satunya memiliki keterampilan yang diperlukan dirinya, masyarakat, bangsa dan negara (UU Nomor 20 Tahun 2003, 2003). Tujuan pendidikan yaitu untuk memenuhi kebutuhan masyarakat dan meningkatkan kualitas sumber daya manusia. Pada setiap tingkatan sekolah dari SD, SMP, SMA atau SMK memiliki tujuan pendidikan yang berbeda. Pendidikan kejuruan adalah pendidikan menengah yang mempersiapkan peserta didik terutama untuk bekerja dalam bidang tertentu (Sistem Pendidikan Nasional, 2003). Pengajar dikatakan berhasil ketika menjadikan peserta didiknya mencapai hasil pembelajaran yang sesuai dengan standart yang telah ditentukan dan mampu memecahkan permasalahan yang ada pada masyarakat (Warsiyah 2016).

Kenyataan yang ada saat ini menunjukkan kualitas lulusan SMK swasta maupun negeri tidak selalu mampu memecahkan permasalahan dan dapat diterima pada dunia kerja sebagaimana yang diharapkan oleh masyarakat. Hal tersebut dapat dilihat pada tingkat pengangguran yang semakin tinggi. Dilihat dari tingkat pendidikan, tingkat pengangguran terbuka untuk Sekolah Menengah Kejuruan masih tertinggi diantara tingkat pendidikan lain, yaitu sebesar 8,63 persen (Badan Pusat Statistik, 2019). Dalam kegiatan evaluasi di BSND, penilaian nasional diarahkan kepada model asesmen yang menuntut kemampuan berpikir yang tidak hanya mengingat (recall), menyatakan kembali (restate), atau merujuk tanpa melakukan pengolahan (recite) yang disebut dengan kemampuan berpikir tingkat tinggi (Musrifah, 2019). Siswa yang memiliki kemampuan tinggi mampu menciptakan makna, membuat pendapat, dan dapat menyimpulkan (Bakry \& Bin Bakar, 2015). Rendahnya kualitas lulusan Sekolah Menengah Kejuruan salah satunya diakibatkan oleh pengajar dalam membuat soal ujian (Arfah \& Muhidin, 2018). Namun kenyataannya, guru Sekolah Menengah Kejuruan umumnya memiliki kemampuan yang berbeda-beda dalam membuat soal High Order Thinking Skill sehingga soal High Order Thinking Skill yang dibuat oleh guru masih perlu ditingkatkan. Dalam meningkatkan kemampuan berpikir tingkat tinggi, tenaga pengajar dituntut mampu 
mendeskripsikan kemampuan berpikir tingkat tinggi sehingga mampu membuat soal ujian dan meningkatkan kemampuan berpikir siswa Sekolah Menengah Kejuruan.

Masa kerja berpengaruh terhadap kinerja pengajar. Hasil penelitian Udiyono (2011) menjelaskan bahwa profesionalitas guru juga berpengaruh terhadap kinerja pengajar. Salah satu kinerja guru adalah kompetensi dalam membuat soal ujian. Kompetensi penting bagi semua guru, misalnya pengembangan kompetensi untuk pemecahan masalah yang efektif atau mendukung pembelajaran siswa (Popov Ed. et al., 2014). Soal ujian yang menggunakan Higher Order Thinking Skill meningkatkan hasil belajar siswa (Widodo \& Kadarwati, 2013). Pembelajaran keterampilan berpikir tingkat tinggi pada soal ujian yang disusun oleh guru mata pelajaran belum mengarah pada keterampilan berpikir tingkat tinggi (Thompson, 2008) Bentuk soal dalam tingkat rendah umumnya ditandai dengan penarikan informasi atau penerapan konsep, pengetahuan pada situasi yang sudah biasa (Yuliati \& Lestari, 2018). Pengetahuan dan pemahaman tersebut sebagai Lower Order Thinking Skills (LOTS) (Ulmer \& Torres, 2007). Tugas sebagai pendidik salah satunya yaitu pengembangan keprofesian (Suwarni, 2011). Faktor demografi, meliputi umur, jenis kelamin, pendidikan, dan pengalaman (Utami \& Kartini, 2017). Salah satu faktor yang memengaruhi hasil lulusan dalam memenuhi tuntutan, yaitu dapat berpikir tingkat tinggi (Batholmeus \& Pop, 2019; Bozkuş \& Bayrak, 2019). Profesional menjadi fokus guru untuk melaksanakan proses pembelajaran dalam kemampuan pada bidangnya (Creasy, 2015). Guru yang belum profesional dikarenakan belum maksimal menguasai bahan pelajaran; belum memakai metode dan media pembelajaran bervariasi; belum memanfaatkan teknologi (Sutrisno \& Aisyah, 2015; Veisson \& Kabaday, 2018). Pengalaman mengajar guru dapat memengaruhi terhadap proses pembelajaran salah satunya yaitu membuat soal ujian yang meningkatkan kemampuan berpikir siswa (Idika \& Onuoha, 2018; Mitits, 2018).

Banyaknya tenaga pengajar dalam proses pembelajarannya yang belum memacu keterampilan berpikir tingkat tinggi siswa SMK disebabkan oleh soal ujian yang masih menggunakan tingkat rendah. Soal ujian yang dibuat oleh guru masih banyak menggunakan soal ujian LOTS (Lower Order Thinking Skill) yang tidak sesuai dengan harapan untuk mencapai lulusan yang berkualitas yang menghasilkan kemampuan berpikir tinggi pada siswa. Hal tersebut umumnya dipengaruhi oleh faktor demografi personaliti dan profesionalitas guru dalam membuat soal ujian. Untuk membuktikan apakah soal ujian yang dibuat guru memengaruhi kemampuan berpikir siswa, maka penelitian ini dilakukan untuk mengetahui pengaruh demografi personaliti dan profesionalitas guru terhadap tingkat berpikir siswa melalui jenis soal ujian yang dibuat oleh guru di Program Teknik Bangunan di SMK se- Jawa Timur.

\section{METODE}

Penelitian ini merupakan penelitian kuantitatif dengan jenis penelitian ex post facto yang bersifat deskriptif dan inferensial. Variabel bebas dalam penelitian ini adalah demografi personality dan profesionalitas guru, variabel terikat adalah tingkat berpikir siswa, dan variabel moderator adalah jenis soal ujian yang dibuat oleh guru. Sekolah Menengah Kejuruan seJawa Timur yang mempunyai program Teknik Bangunan berjumlah 83 sekolah. Populasi dalam penelitian ini adalah seluruh guru program Teknik Bangunan SMK se-Jawa Timur tahun 2019. Berdasarkan jumlah guru SMK se-Jawa Timur dengan program teknik bangunan, maka sampel diambil berdasarkan cluster sampling. Cluster sampling digunakan untuk mengelompokan berdasarkan wilayah geografis (Jaupllari \& Olta Zoto, 2013). Instrumen penelitian pada demografi personality memiliki indikator usia, jenis kelamin, pendidikan, dan masa kerja; indikator profesionalitas adalah kompetensi pedagogik, sosial, profesional, dan kepribadian; tindikator tingkat berpikir adalah LOTS (Lower Order Thingking Skill) dan HOTS (High Order Thingking Skill); indikator jenis soal ujian berdasarkan tingkat Taksonomi Bloom dari C1 (mengingat), C2 (memahami), C3 (menerapkan), C4 (menganalisis), C5 (mengevaluasi), dan C6 (mengkreasi). Teknik pengumpulan data dalam penelitian ini menggunakan angket. Teknik pengumpulan data dengan angket digunakan untuk mengetahui profesionalitas dan demografi personality pada masing-masing siswa. Pengisian angket dilakukan melalui google form sehingga siswa dapat langsung menanggapinya dan menghemat waktu penelitian (Ivankov, 2018). Teknik dokumentasi untuk menggali data demografi personality, tingkat berpikir siswa, dan jenis soal ujian masing-masing guru, data dokumentasi yang diperlukan, yaitu sumber data sekunder (Fonseca, García, \& García, 2013). Teknik analisis data menggunakan analisis deskriptif dan path analysis.

\section{HASIL}

\section{Demografi Personality, Profesionalitas Guru, Tingkat Berpikir Siswa, dan Jenis Soal Ujian}

Hasil analisis untuk Demografi Personality terdiri dari usia, jenis kelamin, masa kerja, pendidikan terakhir dapat dilihat pada gambar 1-4. Hasil analisis untuk Demografi Personality tentang usia guru tahun 2019 pada gambar 1. Banyak guru berusia 51 tahun ke atas dan guru yang paling sedikit berusia 41-50 tahun. Rata-rata guru berusia 51 tahun ke atas. Dengan demikian, guru sudah memiliki banyak pengalaman dalam mengajar. 


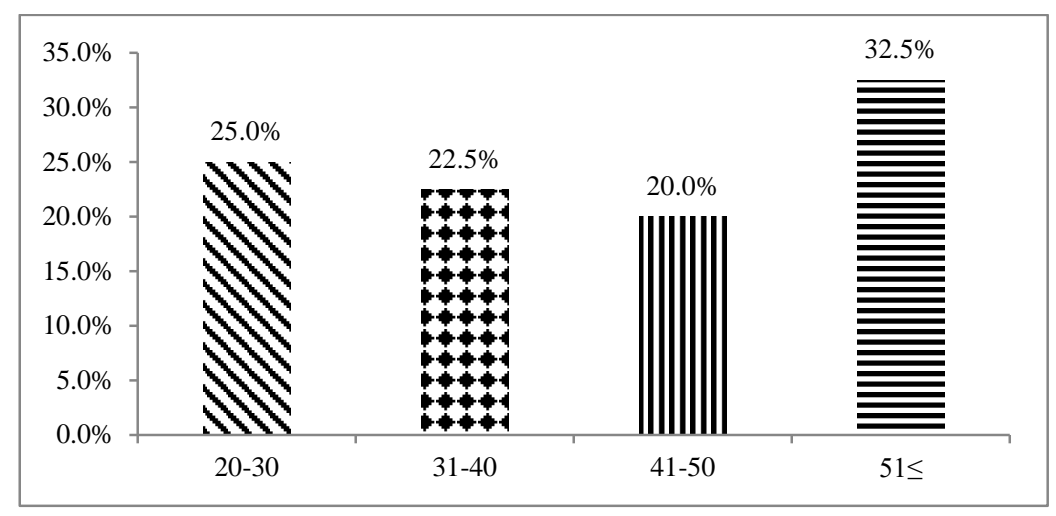

Gambar 1. Usia Guru SMK Program Teknik Bangunan se- Jawa Timur

Guru berjenis kelamin laki-laki berjumlah 65\% dan berjenis kelamin perempuan berjumlah 35\%. Dengan demikian, guru SMK se-Jawa Timur Program Teknik Bangunan, rata-rata berjenis kelamin laki-laki.

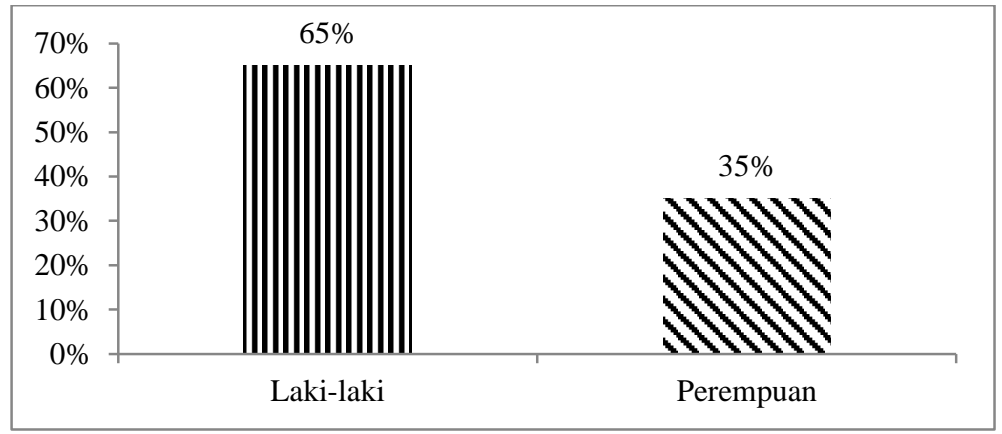

\section{Gambar 2. Jenis Kelamin Guru SMK Program Teknik Bangunan}

Banyak guru yang memiliki tingkat masa kerja lama 21 tahun ke atas dan guru yang paling sedikit adalah masa kerja baru. Rata-rata masa kerja guru adalah masa kerja lama 21 tahun ke atas. Dengan demikian, banyak guru yang sudah memiliki pengalaman.

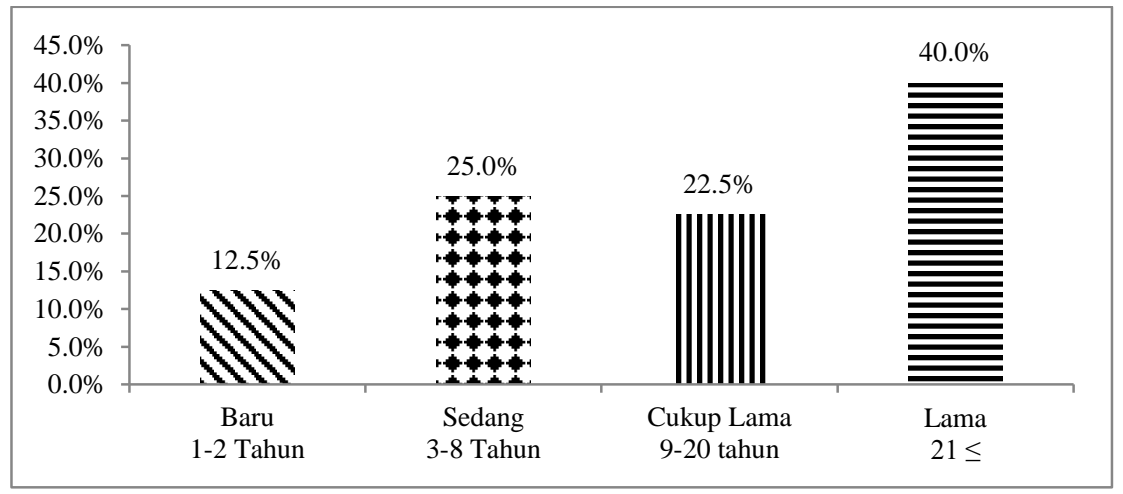

Gambar 3. Masa Kerja Guru SMK Program Teknik Bangunan

Guru yang memiliki status pendidikan S1 lebih banyak daripada S3. Rata-rata status pendidikan guru adalah S1. Dengan demikian, banyak guru SMK se-Jawa Timur pada Program Teknik Bangunan sudah memiliki banyak pengetahuan. Profesionalitas guru yang paling banyak adalah tingkat profesionalitas tinggi dan yang paling sedikit adalah kurang profesional. Rata-rata tingkat profesionalitas guru adalah profesional. Dengan demikian, banyak guru yang memiliki tingkat profesional. 


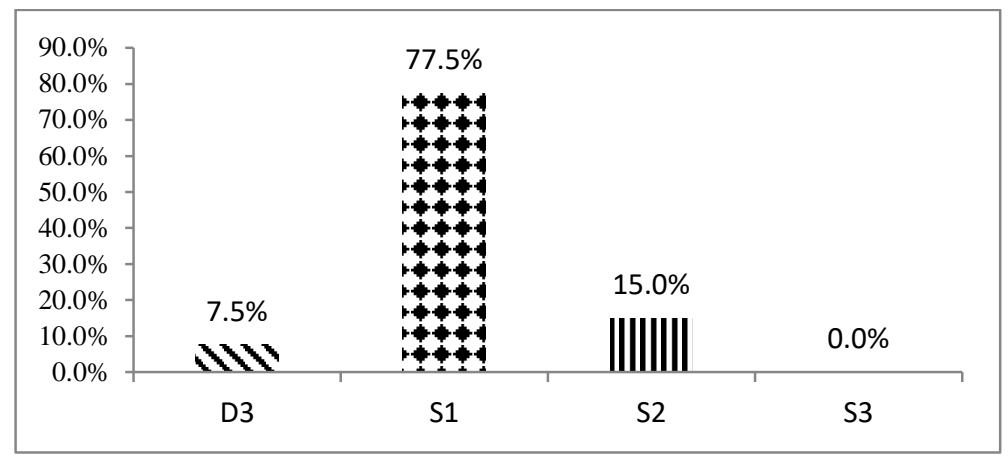

Gambar 4. Status Pendidikan Guru SMK Program Teknik Bangunan

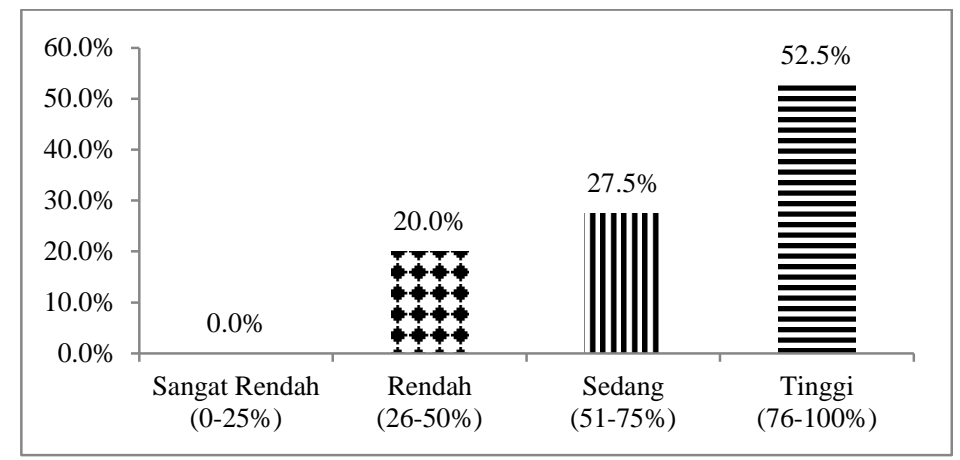

Gambar 5. Profesionalitas Guru

Dapat dilihat bahwa tingkat berpikir pada siswa untuk tingkat rendah adalah 76 dan untuk tingkat berpikir tinggi HOTS dalah 72. Rata-rata tingkat berpikir siswa SMK se-Jawa Timur Program Teknik Bangunan berdasarkan ranah Taksonomi Bloom memiliki tingkat berpikir rendah.

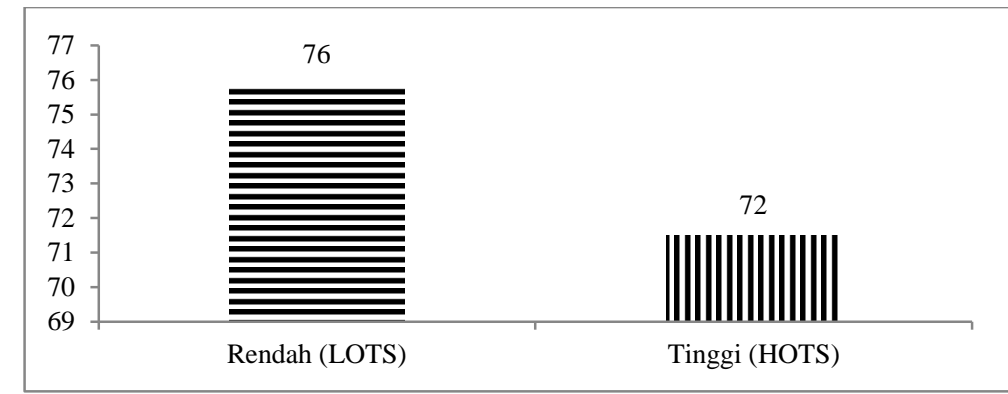

\section{Gambar 6. Tingkat Berpikir Siswa SMK Program Teknik Bangunan}

Soal ujian yang paling banyak dibuat oleh guru pada ranah menerapkan (C3) dan yang paling sedikit adalah ranah mengkreasi (C6). Rata-rata soal yang dibuat guru adalah ranah menerapkan (C3). Dengan demikian, guru dalam membuat soal ujian sudah berada tingkat tinggi dengan kriteria baik.

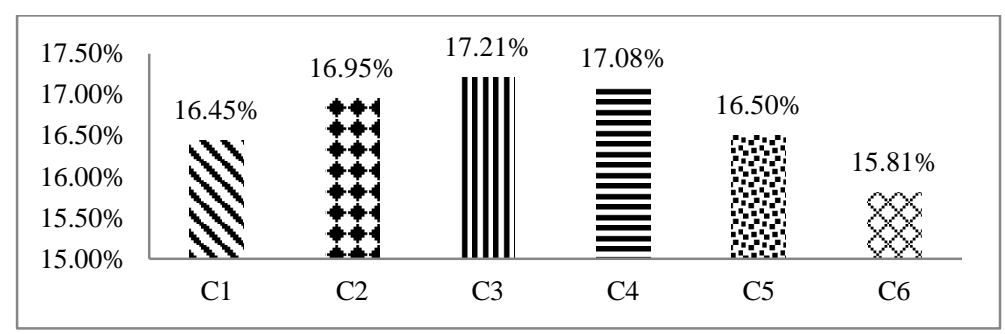

Gambar 7. Jenis Soal Ujian yang dibuat oleh Guru 


\section{Pengaruh Demografi Personality dan Profesionalitas Guru terhadap Tingkat Berpikir Siswa dengan Jenis Soal Ujian yang Dibuat Guru}

Tabel 1. Rangkuman Nilai Probabilias pada Analisis Menggunakan SPSS

\begin{tabular}{|c|c|c|c|c|}
\hline \multirow{2}{*}{$\begin{array}{l}\text { Rumusan Masalah } \\
\text { Demografi personality terhadap tingkat berpikir siswa }\end{array}$} & \multirow{2}{*}{$\begin{array}{r}\text { Sebutan } \\
\mathrm{X} 1 \rightarrow \mathrm{Z}\end{array}$} & \multicolumn{3}{|c|}{$\begin{array}{l}\text { Nilai } \\
\text { Probabilitas }\end{array}$} \\
\hline & & 0,407 & $>$ & 0,05 \\
\hline Profesionalitas terhadap tingkat berpikir siswa & $\mathrm{X} 2 \rightarrow \mathrm{Z}$ & 0,971 & $>$ & 0.05 \\
\hline Dengan jenis soal ujian yang dibuat guru terhadap tingkat berpikir siswa & $\mathrm{Y} \rightarrow \mathrm{Z}$ & 0,005 & $\leq$ & 0.05 \\
\hline $\begin{array}{l}\text { Demografi personality dan profesionalitas gutu terhadap tingkat berpikir siswa dengan jenis soal } \\
\text { ujian yang dibuat guru }\end{array}$ & $\mathrm{X} 1 \& \mathrm{X} 2 \& \mathrm{Y} \rightarrow \mathrm{Z}$ & 0,004 & $\leq$ & 0.05 \\
\hline Demografi personality terhadap Jenis soal ujian yang dibuat guru & $\mathrm{X} 1 \rightarrow \mathrm{Y}$ & 0,021 & $\leq$ & 0.05 \\
\hline Profesionalitas terhadap jenis soal ujian yang dibuat guru & $\mathrm{X} 2 \rightarrow \mathrm{Y}$ & 0,000 & $\leq$ & 0.05 \\
\hline Demografi personality dan profesionalitas guru terhadap jenis soal ujian yang dibuat guru & $\mathrm{X} 1 \& \mathrm{X} 2 \rightarrow \mathrm{Y}$ & 0,001 & $\leq$ & 0.05 \\
\hline
\end{tabular}

Nilai probabilitas untuk pengujian secara simultan lebih kecil dari 0,05 maka artinya adalah Ha diterima dan Ho ditolak. artinya koefisien analisis jalur adalah signifikan. Dengan demikian, pengujian secara individu untuk setiap variabel bebas dengan variabel terikat dapat dilanjutkan. Demografi personality guru tidak berpengaruh terhadap tingkat berpikir siswa begitupun profesionalitas guru tidak berpengaruh terhadap tingkat berpikir siswa, namun jenis soal ujian yang dibuat oleh guru berpengaruh terhadap tingkat berpikir siswa. Semakin jenis soal ujian HOTS yang mencakup C4, C5, dan C6 maka tingkat berpikir siswa semakin tinggi. Siswa dapat menyelesaikan permasalahan HOTS yang diberikan oleh guru yang menjadikan siswa berpikir tingkat tinggi karena terbiasanya siswa menghadapi soal yang merangsang untuk menganalisis, mengevaluasi, dan mengkreasi atau menciptakan.

\section{Pengaruh Demografi Personality dan Profesionalitas Guru terhadap Jenis Soal Ujian yang dibuat oleh Guru}

Tabel. 2. Rangkuman Dekomposisi Dari Koefisien Jalur

\begin{tabular}{|c|c|c|c|c|}
\hline \multirow{2}{*}{ Pengaruh Variabel } & \multicolumn{2}{|r|}{ Pengaruh Kausal } & \multirow{2}{*}{ Sisa $\varepsilon_{1}$ dan $\varepsilon_{2}$} & \multirow{2}{*}{ Total } \\
\hline & Langsung & Tidak Langsung Melalui Y & & \\
\hline X1 terhadap Z & 0,194 & 0,451 & & $\begin{array}{l}3,763 \% \\
20,34 \%\end{array}$ \\
\hline $\mathrm{X} 2$ terhadap Z & 0,009 & 0,404 & & $\begin{array}{l}0,01 \% \\
16,32 \%\end{array}$ \\
\hline $\mathrm{X} 1, \mathrm{X} 2, \mathrm{Y}$ terhadap Z & 0,305 & & 0,695 & $9,30 \%$ \\
\hline X1 terhadap Y & 0,153 & & & $2,34 \%$ \\
\hline $\mathrm{X} 2$ terhadap $\mathrm{Y}$ & 0,826 & & & $68,23 \%$ \\
\hline $\mathrm{X} 1 \mathrm{X} 2$ terhadap $\mathrm{Y}$ & 0,300 & & 0,70 & $9 \%$ \\
\hline
\end{tabular}

Demografi personality, profesionalitas terhadap jenis soal ujian yang dibuat guru memiliki nilai probabilitas (sig) kurang dari 0,05 maka artinya adalah Ha diterima dan Ho ditolak. Artinya, koefisien analisis jalur adalah signifikan. Dengan demikian, demografi personality dan profesionalitas guru berpengaruh terhadap jenis soal ujian yang dibuat. Secara simultan, ada pengaruh secara signifikan maka dapat diuji secara individu antar variabel. Demografi personality guru berpengaruh terhadap jenis soal ujian yang dibuat oleh guru secara langsung berkontribusi sebesar 2,34\%. Guru membuat soal ujian yang High Order Thinking Skill yaitu guru yang sudah memiliki pengalaman yang banyak atau lama dibandingkan dengan yang pengalaman yang baru. Cenderung guru yang memiliki pengalaman kerja baru lebih belum berpengalaman membuat soal ujian sehingga perlu diadakan sebuah pelatihan dan pengembangan pada dirinya. Pengembangan dan pelatihan pada dirinya ini akan membuat guru menjadi profesionalitas dalam bekerja karena profesionalitas guru berpengaruh terhadap jenis soal yang dibuat oleh guru yang berkontribusi secara langsung sebesar 68,23\%. Semakin profesionalitas guru, maka semakin High Order Thingking Skill soal yang dibuat mencakup C4, C5, dan C6. Jenis soal ujian yang dibuat oleh guru berengaruh terhadap tingkat berpikir siswa yang berkontribusi secara langsung sebesar 20,33\%. Sehingga guru perlu diadakan pelatihan dan pengembangan diri agar memiliki pengalaman dan profesionalitas yang tinggi agar dalam membuat soal ujian dapat mencakup Taksonomi Bloom yang High Order Thinking Skill yaitu menganalisis, mengevaluasi, dan mengkreasi. Kontribusi secara simultan sebesar $85 \%$ dengan sisanya $15 \%$ merupakan pengaruh yang datang dari faktor-fakor yang lain. 


\section{PEMBAHASAN}

\section{Demografi Personality, Profesionalitas Guru, Tingkat Berpikir Siswa, dan Jenis Soal Ujian}

Guru yang berjenis kelamin laki-laki memiliki kemampuan untuk bekerjasama, berkomunikasi, dan ketertiban sosial di masyarakat (Wijaksono, Hubeis, \& Saptono, 2017). Perbedaan lain dalam jenis kelamin bahwa pembuatan soal yang beragam yang menggunakan ranah kognitif tingkat tinggi, secara terukur lebih penting bagi perempuan daripada laki-laki. Dapat dijelaskan bahwa guru yang berjenis kelamin laki-laki kurang mementingkan pembuatan soal yang beragam dalam ranah kogitif tingkat tinggi, namun memiliki kemampuan untuk bekerjasama dan berkomunikasi lebih unggul sehingga kemampuan dalam mengajar untuk merangsang kemampuan berpikir tingkat tinggi siswa lebih baik.

Pendidik harus memiliki kualifikasi minimum dan sertifikasi sesuai dengan jenjang kewenangan mengajar, sehat jasmani dan rohani, serta memiliki kemampuan untuk mewujudkan tujuan pendidikan nasional (Sistem Pendidikan Nasional, 2003). Selain syarat untuk bekerja harus minimal lulusan D3 atau S1 yang harus menunjang kemampuan mengajar adalah pengalaman kerja. Selama masa kerjanya guru dituntut menjalankan tugasnya sebagai pendidik dan melakukan penelitian, mengikuti pelatihan, dan membimbing. Beban kerja mencakup membimbing, melakukan penelitian, melakukan tugas tambahan. Sehingga banyak pengalaman yang didapat guru selama masa kerjanya (UU No 14 Tahun 2005, 2005). Pengakuan guru sebagai tenaga yang profesional dibuktikan dengan sertifikasi pendidik. Profesionalitas pendidik untuk memahami kemampuan siswa dalam berpikir dan meningkatkan keahlian dalam mengajar atau akan menjadi sebuah prestasi pada guru (Nolan \& Molla, 2019). Profesionalitas sangat menentukan keahlian dalam pengetahuan dan keterampilan mengajar yang dimiliki oleh guru sehingga pengembangan profesional harus dilatih kembali (Karataş, 2019). Sertifikasi pendidik adalah bukti bahwa guru tersebut profesional. Keprofesionalan guru adalah kemampuan dalam meningkatkan kemampuan berpikir tingkat tinggi siswa.

Dalam meningkatkan kemampuan berpikir tingkat tinggi siswa, maka guru harus memfasilitasi siswa untuk menjadi kreatif dan kritis dalam menyelesaikan masalah yang lebih baik dengan cara memberikan suatu masalah yang memungkinkan siswa untuk menggunakan kemampuan berpikir tingkat tinggi (Ariandari, 2015). Memberikan pertanyaan Higher Order Thinking Skill Berbasis Pemecahan Masalah untuk Meningkatkan Hasil Belajar Berorientasi Pembentukan Karakter Siswa. pada siswa dapat medorong pemikiran kritis dan kreatif dan siswa mampu menjawab pertanyaan tersebut (Narayanan \& Adithan, 2015). Memiliki kemampuan berpikir tingkat rendah karena hanya mampu menjawab permasalah pada taraf C1-C3. Ada beberapa siswa yang mampu menjawab permasalahan dalam taraf High Order Thinking Skill, namun hasil dari tingkat berpikir siswa masih dalam kategori rendah.

Tingkat ranah kognitif menerapkan C3 merupakan tingkat kognitif yang sering digunakan oleh pengajar dalam pembuatan soal karena mendekati pada High Order Thinking Skill. Dalam setiap materi pembahasan, ada bentuk soal dari tingkat rendah ke tingkat tinggi yang berdasarkan ranah taksonomi bloom ( et al., 2019). SMK harus dapat mencapai level 6 yaitu tingkat menerapkan (KKNI, 2015). Dengan demikian, soal ujian dengan kriteria baik dan sudah memenuhi kriteria KKNI, yaitu tingkat menerapkan $\mathrm{C} 3$. Hal tersebut dikarenakan mengacu pada materi atau jenis mata pelajaran dominan pada tingkat menerapkan C3. Pengalaman kerja ada didalam masa kerja dan profesionalitas karena semakin masa kerja lama dan profesionalitas maka memiliki banyak pengalaman kerja dalam meningkatkan kemampuan siswa. Meningkatkan kemampuan berpikir siswa dengan jenis soal Higher Order Thinking Skill Berbasis Pemecahan Masalah untuk Meningkatkan Hasil Belajar Berorientasi Pembentukan Karakter Siswa. yang sangat penting untuk pendidikan dan pengembangan karena lulusan sekolah memerlukan keterampilan, seperti kreativitas, imajinasi, dan inovasi untuk mengatasi setiap tantangan produksi dan pengembangan yang muncul dalam kehidupan mereka termasuk dunia kerja (Mitana, 2018). Kemampuan guru masih dalam taraf cukup profesional dalam kegiatan yang melibatkan analisis berdasarkan Taksonomi Bloom, dan dalam kegiatan yang meningkatkan keterampilan di tingkat tinggi sehingga perlu menekankan peningkatan guru dalam meningkatkan kemampuan berpikir siswa dengan memberikan sebuah permasalahan (Soal ujian) yang Higher Order Thinking Skill Berbasis Pemecahan Masalah untuk Meningkatkan Hasil Belajar Berorientasi Pembentukan Karakter Siswa (Asiroglu \& Akran, 2018). Meningkatkan kemampuan berpikir siswa dengan jenis soal yang dibuat oleh guru masih dalam tingkat rendah (Köksal \& Ulum, 2018).

Generasi masa kerja baru merupakan generasi muda yang memiliki karakteristik kreatif dan ambisius (Kurniawati, 2018). Oleh karena itu, dalam meningkatkan kemampuan berpikir tinggi siswa sangat kreatif. Faktor demografi personality tidak memengaruhi kemampuan berpikir siswa maupun kemampuan dalam mengajar. Jenis kelamin laki-laki lebih bersemangat dalam bekerja sehingga banyak laki-laki yang melaksanakan pekerjaan (Mackay, Perry, Ramanathan, \& Wong, 2010). Keterampilan Berpikir Rendah menjadi faktor dominan dalam tingkat berpikir siswa (Kanokpermpoon, 2019). Semakin lama masa kerja semakin bertambah pula usia sehingga keahlian seseorang, kecepatan, kecerdasan, dan tenaga menyusut dari waktu ke waktu. Berdasarkan hasil pembahasan di atas dapat dijelaskan bahwa tidak ada pengaruh yang signifikan antara masa kerja baru, masa kerja sedang, masa kerja cukup lama, dan masa kerja lama terhadap tingkat berpikir siswa. Guru dalam mengajar program teknik dapat mengajukan lebih banyak pertanyaan dalam tingkat analisis dan sintesis daripada sekedar mengingat fakta di tingkat pengetahuan (Narayanan \& Adithan, 2015).

Pengajar mengakui bahwa jenis soal yang Higher Order Thinking Skill Berbasis Pemecahan Masalah untuk Meningkatkan Hasil Belajar Berorientasi Pembentukan Karakter Siswa sangat memengaruhi dalam kemampuan berpikir tingkat tinggi siswa (Nevid \& McClelland, 2013). Jenis soal ujian sangat berpengaruh dalam meningkatkan kemampuan siswa hal demikian akan terbiasa dalam menghadapi permasalahan di masyarakat yang tingkat tinggi (Fauzi, Dirgeyase, \& Priyatno, 
2019). Soal ujian yang diberikan oleh guru masih dalam tingkat rendah hal ini akan menghambat kemampuan berpikir siswa (Chandio, Pandhiani, \& Iqbal, 2016). Memberikan pertanyaan yang HOTS pada siswa dapat medorong pemikiran kritis dan kreatif (Narayanan \& Adithan, 2015). Soal ujian yang harus dibuat oleh guru SMK program teknik bangunan adalah dalam bentuk High Order Thinking Skill karena akan memengaruhi tingkat berpikir siswa tersebut. Agar siswa dapat menghadapi dunia kerja dan menurunkan angka pengangguran, maka guru harus mampu membuat soal ujian yang High Order Thinking Skill.

Pertanyaan ujian yang efisien harus mencakup berbagai tingkat kesulitan untuk merujuk pada berbagai kemampuan peserta didik (Jones, Harland, Reid, \& Bartlett, 2009). Ada berberapa soal ujian dalam salah satu pembelajaran hanya terfokuskan pada kemampuan berpikir tingkat rendah (Ali Al-hasanat, 2016). Demografi personality dan profesionalitas berpengaruh dalam membuat soal ujian. Soal ujian yang dibuat oleh guru masih dalam taraf rendah, namun ada pertanyaan pada dimensi kognitif mengutamakan tingkat mengingat dan memahami demografi personality dan profesionalitas pada tingkat rendah ( et al., 2019). Pendidik harus mengemukakan pertanyaan untuk semua level kognitif dan menambah level berpikir siswa yang lebih tinggi dengan memberikan pertanyaan yang awalnya menuntut keterampilan berpikir dasar dan sederhana dan kemudian berkembang menjadi pertanyaan kompleks yang menuntut keterlibatan dengan pertanyaan melalui inferensi, penalaran, evaluasi, dan penyusunan (Jaiswal, 2019). Semakin profesionalitas guru dan semakin lama masa kerjanya maka soal yang dibuat dalam bentuk HOTS. Maka dari itu, perlu ditingkatkan pengalaman kerja dan profesionalitas guru dengan cara perbanyak pelatihan dan uji kompetensi.

Tidak ada perbedaan yang signifikan dalam membuat jenis soal ujian dan meningkatkan kemampuan siswa yang berdasarkan pada demografi personality (Semerci \& Aydın, 2018). Demografi personality (masa kerja) berpengaruh secara signifikan terhadap bentuk pertanyaan, seseorang yang memiliki pengalaman yang lebih lama maka dalam memberikan pertanyaan sudah pada tingkat tinggi (Vinney, Friberg, \& Smyers, 2018). Pertanyaan tingkat tinggi adalah alat praktis untuk mendorong pemikiran dan meningkatkan keterampilan kognitif lainnya seperti pemecahan masalah dan pengambilan keputusan yang dipengaruhi pengalam kerja guru (Freahat \& Smadi, 2014). Pertanyaan tingkat tinggi mungkin asing bagi siswa karena menuntut jawaban melalui penalaran, pengambilan keputusan, analisis, sintesis, dan pemikiran kritis karena pengalaman kerja guru dalam menerapkan soal ujian High Order Thinking Skill kurang (Ordem, 2016; Zoller \& Tsaparlis, 1997). Semakin masa kerjanya lama maka soal yang dibuat semakin dalam jenis soal ujian High Order Thinking Skill. Maka dari itu, perlu ditingkatkan pengalaman kerja untuk guru.

Profesionalitas guru dalam mengajar akan berpengaruh dalam membuat soal High Order Thinking Skill. Hal tersebut dikarenakan guru dapat mendorong siswa untuk mengembangkan kemampuan berpikirnya. Dengan demikian, guru wajib mengembangkan keterampilan mengajar (Muehleck, Smith, \& Allen, 2014). Penting bagi seorang pendidik untuk mengembangkan keprofesionalitasnya agar pada setiap siswa dapat menjadi mandiri dan memiliki kemampuan berpikir tingkat tinggi karena dalam proses pembelajaran salah satunya yaitu kegiatan evaluasi dengan memberikan soal yang HOTS akan memberikan kemampuan berpikir tingkat tinggi (Smith \& Darvas, 2017). Guru harus mendorong untuk menggunakan soal yang bersifat merangsang kemampuan kritis siswa (Nasrollahi, Krishnasamy, \& Noor, 2015). Kemampuan berpikir tingkat tinggi yang harus diajarkan oleh siswa yaitu dengan melalui memberikan permasalahan yang merangsang pemikiran siswa yaitu pemikiran yang kreatif dan kritis dalam pelajaran (Rahman \& Manaf, 2017). Semakin profesional guru maka semakin tinggi tingkat berpikir dalam membuat soal ujian test. Hal tersebut disebabkan karena sering pelatihan, seminar, studi lanjut, penelitian, dan mengajar. Tenaga pengajar memiliki sertifikasi sebagai pengajar.

\section{SIMPULAN}

Berdasarkan hasil penelitian dan pembahasan yang telah dideskripsikan dapat diambil simpulan (1) demografi personality dan profesionalitas guru yang ada di SMK se-Jawa Timur Program Teknik Bangunan yaitu rata-rata jenis kelamin yaitu laki-laki, status pendidikan rata-rata sarjana, rata-rata berusia di atas 40-60 tahun sehingga masa kerjanya pada masa kerja lama sekitar 21 tahun ke atas maka sudah memiliki sertifikasi pendidik yaitu sebagai bukti bahwa guru tersebut sudah profesiona; (2) tingkat berpikir siswa masih pada tingkat rendah, yaitu siswa hanya mampu menjawab pertanyaan pada ranah C1-C3.; (3) jenis soal ujian yang dibuat oleh guru adalah LOTS, namun yang paling banyak pada ranah kognitif C3 yaitu menerapakan dengan kriteria baik dan sudah memenuhi kriteria KKNI untuk SMK yaitu tingkat menerapkan; (4) tidak ada pengaruh yang signifikan demografi personality (masa kerja) dan profesionalitas guru terhadap tingkat berpikir siswa; (5) Ada pengaruh yang signifikan jenis soal ujian yang dibuat oleh guru terhadap tingkat berpikir siswa. Sehingga semakin Higher Order Thinking Skill Berbasis Pemecahan Masalah untuk Meningkatkan Hasil Belajar Berorientasi Pembentukan Karakter Siswa. soal yang dibuat oleh guru maka semakin tinggi tingkat berpikir siswa; (6) ada pengaruh yang signifikan demografi personality dan profesionalitas guru terhadap tingkat berpikir siswa dalam soal ujian yang dibuat oleh guru; (7) ada pengaruh yang signifikan demografi personality dan profesionalitas guru terhadap jenis soal ujian yang dibuat oleh guru. 
Berdasarkan hasil penelitian, penulis memberikan saran sebagai berikut. Pertama, diharapkan bagi guru dalam menyusun soal ujian untuk tingkat ranah mengetahui $(\mathrm{C} 1)$ dan ranah memahami $(\mathrm{C} 2)$ harus dikurangi dan membuat soal dengan tingkat lebih tinggi yang sesuai dengan kurikulum seperti pada tingkat ranah menerapkan (C3), menganalisis (C4), mengevaluasi (C5), dan menciptakan (C6). Agar dapat menunjang dan merangsang kemampuan peserta didik sehingga dapat memenuhi kebutuhan masyarakat. Selain itu, agar dapat mengurangi pengangguran yang ada di Indonesia dan mempersiapkan siswa SMK ke dunia kerja. Kedua, Prodi dan sekolah sebaiknya sering megadakan pelatihan, seminar, studi lanjut, penelitian, dan pengabdian masyarakat sehingga dapat menunjang keberhasilan peserta didik dan kemajuan jurusan.

\section{DAFTAR RUJUKAN}

Ali Al-Hasanat, H. A. (2016). Analyzing Assessment Questions in an Arabic Textbook (Communication Skills) for Eight Grade in Jordan According to Bloom's Taxonomy of Levels of Knowledge Aims. World Journal of Education, 6(2). https://doi.org/10.5430/wje.v6n2p68

Arfah, M., \& Muhidin, S. A. (2018). Hubungan Kompetensi Profesional Guru dengan Hasil Belajar Siswa SMK Bidang Keahlian Bisnis dan Manajemen di Kota Bandung. Jurnal Pendidikan Manajemen Perkantoran, 3(2), 42. https://doi.org/10.17509/jpm.v3i2.11763

Ariandari, W. P. (2015). Mengintegrasikan Higher Order Thinking dalam Pembelajaran Creative Problem Solving. Seminar Nasional Matematika dan Pendidikan Matematika Uny 2015, 489-496.

Asiroglu, S., \& Akran, S. K. (2018). The Readiness Level of Teachers in Science, Technology, Engineering and Mathematics Education. Universal Journal of Educational Research, 6(11), 2461-2470. https://doi.org/10.13189/ujer.2018.061109

Bakry, B., \& Bin Bakar, M. N. (2015). The Process of Thinking among Junior High School Student in Solving HOTS Question. International Journal of Evaluation and Research in Education (IJERE), 4(3), 138. https://doi.org/10.11591/ijere.v4i3.4504

Batholmeus, P., \& Pop, C. (2019). Enablers of Work-Integrated Learning in Technical Vocational Education and Training Teacher Education. International Journal of Work-Integrated Learning, 20(2), 147-159.

Bozkuş, K., \& Bayrak, C. (2019). The Application of the Dynamic Teacher Professional Development Through Experimental Action Research. International Electronic Journal of Elementary Education, 11(4), 335-352. https://doi.org/10.26822/iejee.2019450792

Chandio, M. T., Pandhiani, S. M., \& Iqbal, S. (2016). Bloom's Taxonomy: Improving Assessment and Teaching-Learning Process. Journal of Education and Educational Development, 3(2), 203. https://doi.org/10.22555/joeed.v3i2.1034

Creasy, K. (2015). Defining Professionalism in Teacher Education Programs. Online Submission, 2(2), $23-25$.

Fauzi, K. M. A., Dirgeyase, I. W., \& Priyatno, A. (2019). Building Learning Path of Mathematical Creative Thinking of Junior Students on Geometry Topics by Implementing Metacognitive Approach. International Education Studies, $12(2), 57$. https://doi.org/10.5539/ies.v12n2p57

Fonseca, A. A., García, C. L. A., \& García, M. C. V. (2013). Reliability of a Questionnaire to Determine Non-Specific Low Back Pain and its Characteristics in School Children Aged 7 to 12 Years. Revista de La Sociedad Espanola Del Dolor, 20(5), 207-215. https://doi.org/10.4321/S1134-80462013000500002

Freahat, N. M., \& Smadi, O. M. (2014). Lower-order and Higher-order Reading Questions in Secondary and University Level EFL Textbooks in Jordan. Theory and Practice in Language Studies, 4(9). https://doi.org/10.4304/tpls.4.9.1804-1813

Idika, E. O., \& Onuoha, J. C. (2018). Influence of Economics Teachers' Personality on Secondary School Students' Classroom Performance in Public Secondary Schools in Nsukka Local Government Area of Enugu State. Journal of Social Science Education, 17(3), 100-106. https://doi.org/10.4119/UNIBI/jsse-v17-i3-1667

Ivankov, P. (2018). Quantization of Noncompact Coverings and its Physical Applications. Journal of Physics: Conference Series, 965(1). https://doi.org/10.1088/1742-6596/965/1/012020

Jaiswal, P. (2019). Using Constructive Alignment to Foster Teaching Learning Processes. English Language Teaching, 12(6), 10. https://doi.org/10.5539/elt.v12n6p10

Jaupllari, S., \& Olta Zoto. (2013). An Assessment of Demand for Imports through the VECM Model Metodology. Journal of Knowledge Management, Economics and Information Technology, III(6), 1-17.

Jones, K. O., Harland, J., Reid, J. M. V., \& Bartlett, R. (2009). Relationship Between Examination Questions and Bloom's Taxonomy. Proceedings - Frontiers in Education Conference, FIE. https://doi.org/10.1109/FIE.2009.5350598

Kanokpermpoon, M. (2019). Thinking Skills in Practice: A Case Study of an English Curriculum at a Thai University. LEARN Journal: Language Education and Acquisition Research Network, 12(2), 49-63.

Karataş, İ. H. (2019). Principles of Professionalism in School Principalship. Universal Journal of Educational Research, 7(2), 588-599. https://doi.org/10.13189/ujer.2019.070232

KKNI. (2015). Paradigma Capaian Pembelajaran. Direktorat Jendral Pembelajaran dan Kemahasiswaan Kementerian Riset, Teknologi, dan Pendidikan Tinggi Republik Indonesia.

Köksal, D., \& Ulum, Ö. G. (2018). Language Assessment Through Bloom's Taxonomy. Journal of Language and Linguistic Studies, 14(2), 76-88.

Kurniawati, I. D. (2018). Masa Kerja dengan Jobengagement pada Karyawan. Jurnal Ilmiah Psikologi Terapan, 2 (2), $311-324$. 
Mackay, M. H., Perry, M., Ramanathan, K., \& Wong, G. C. (2010). 45 Oral Sex and Gender Differences in Critical Time-toTreatment Intervals among ST-Elevation MI Patients. European Journal of Cardiovascular Nursing, 9(1_suppl), S5-S6. https://doi.org/10.1016/s1474-5151(10)60027-8

Mitana, J. (2018). Assessment of Higher Order Thinking Skills: A Case of Uganda Primary Leaving Examinations. African Educational Research Journal, 6(4), 240-249. https://doi.org/10.30918/aerj.64.18.083

Mitits, L. (2018). Multilingual Students in Greek Schools: Teachers' Views and Teaching Practices. Journal of Education and E-Learning Research, 5(1), 28-36. https://doi.org/10.20448/journal.509.2018.51.28.36

Muehleck, J. K., Smith, C. L., \& Allen, J. M. (2014). Understanding the Advising Learning Process Using Learning Taxonomies. NACADA Journal, 34(2), 63-74. https://doi.org/10.12930/nacada-13-013

Musrifah, M. (2019). Analisis Kritis Permasalahan Pendidikan Islam Indonesia di Era Global. Journal of Islamic Studies and Humanities, 3(1), 67. https://doi.org/10.21580/jish.31.2341

Narayanan, S., \& Adithan, M. (2015). Analysis of Question Papers in Engineering Courses with Respect to HOTS (Higher Order Thinking Skills). American Journal of Engineering Education (AJEE), 6(1), 1-10. https://doi.org/10.19030/ajee.v6i1.9247

Nasrollahi, M. A., Krishnasamy, P. K. N., \& Noor, N. M. (2015). Process of Implementing Critical Reading Strategies in an Iranian EFL Classroom: An Action Research. International Education Studies, 8(1), 9-16. https://doi.org/10.5539/ies.v8n1p9

Nevid, J. S., \& McClelland, N. (2013). Using Action Verbs as Learning Outcomes: Applying Bloom's Taxonomy in Measuring Instructional Objectives in Introductory Psychology. Journal of Education and Training Studies, 1(2). https://doi.org/10.11114/jets.v1i2.94

Nolan, A., \& Molla, T. (2019). Supporting Teacher Professionalism Through Tailored Professional Learning. London Review of Education, 17(2), 126-140. https://doi.org/10.18546/LRE.17.2.03

Ordem, E. (2016). Developing Critical-Thinking Dispositions in a Listening/Speaking Class. English Language Teaching, 10(1), 50. https://doi.org/10.5539/elt.v10n1p50

Paida, A. (2018). Pengaruh Kompetensi Pedagogik, Kompetensi Profesional dan Kepuasan Kerja terhadap Kinerja Guru di SMK Negeri 4 Makassar. Konfiks : Jurnal Bahasa dan Sastra Indonesia, 4(2), 119. https://doi.org/10.26618/jk.v4i2.1334

Popov Ed., N., Wolhuter Ed., C., Ermenc Ed., K. S., Hilton Ed, G., Ogunleye Ed., J., \& Chigisheva Ed., O. (2014). Education's Role in Preparing Globally Competent Citizens. BCES Conference Books, Volume 12. Bulgarian Comparative Education Society.

Rahman, S. A., \& Manaf, N. F. A. (2017). A Critical Analysis of Bloom's Taxonomy in Teaching Creative and Critical Thinking Skills in Malaysia through English Literature. English Language Teaching, 10(9), 245. https://doi.org/10.5539/elt.v10n9p245

Semerci, A., \& Aydın, M. K. (2018). Examining High School Teachers' Attitudes towards ICT Use in Education. International Journal of Progressive Education, 14(2), 93-105. https://doi.org/10.29329/ijpe.2018.139.7

Sistem Pendidikan Nasional. (2003). Undang-Undang No.20 Tahun 2003. Departemen Pendidikan Nasional, 1-33. Retrieved from http://kelembagaan.ristekdikti.go.id/wp-content/uploads/2016/08/UU_no_20_th_2003.pdf

Smith, V., \& Darvas, J. (2017). Encouraging Student Autonomy Through Higher Order Thinking Skills. Journal of Instructional Research, 6(1). https://doi.org/10.9743/jir.2017.5

Sutrisno, B., \& Aisyah, A. (2015). Profil Pengembangan Profesional Guru. Jurnal VARIDIKA, 24(4). https://doi.org/10.23917/varidika.v24i4.701

Suwarni, S. (2011). Analisis Kebijakan Nasional tentang Jabatan Fungsional Guru dan Angka Kredit pada SMA Negeri di DKI Jakarta. ATIKAN: Jurnal Kajian Pendidikan, 1(1), 123-140.

Thompson, T. (2008). Mathematics Teachers' Interpretation of Higher-Order Thinking in Bloom's Taxonomy. International Electronic Journal of Mathematics Education, 3, 96-109.

Ulmer, J., \& Torres, R. (2007). A Comparison Of The Cognitive Behaviors Exhibited By Secondary Agriculture and Science Teachers. Journal of Agricultural Education, 48(4), 106-116. https://doi.org/10.5032/jae.2007.04106

Utami, L. D., \& Kartini, K. (2017). Faktor Demografis, Personality Traits, dan Overconfidence (Survey terhadap investor saham di Yogyakarta). Jurnal Siasat Bisnis, 20(2), 181-196. https://doi.org/10.20885/jsb.vol20.iss2.art6

UU No 14 Tahun 2005, R. (2005). Undang-undang Guru dan Dosen. Produk Hukum, 1-26. https://doi.org/http://dx.doi.org/10.1016/S0167-2991(08)63816-1

UU Nomor 20 Tahun 2003. (2003). Undang-Undang No.20 Tahun 2003. Departemen Pendidikan Nasional.

Veisson, M., \& Kabaday, A. (2018). Exploring the Preschool Teachers' Views on Professionalism, Quality of Education and Sustainability: International Study in Estonia and Turkey. Journal of Teacher Education for Sustainability, $20,5-18$. https://doi.org/10.2478/jtes-2018-0011

Vinney, L. A., Friberg, J. C., \& Smyers, M. (2018). Case-Based Perspective-Taking as a Mechanism to Improve Metacognition and Higher-Level Thinking in Undergraduate Speech-Language Pathology Students. Journal of the Scholarship of Teaching and Learning, 19(3). https://doi.org/10.14434/josotl.v19i2.24006 
Warsiyah. (2016). Manajemen Mutu Dalam Pengembangan Kompetensi Guru (Studi pada Madrasah Aliyah Negeri di Kota Sragen). Wahana Akademika, 3(1), 77-97.

Widodo, T., \& Kadarwati, S. (2013). Higher Order Thinking Berbasis Pemecahan Masalah untuk Meningkatkan Hasil Belajar Berorientasi Pembentukan Karakter Siswa. Jurnal Cakrawala Pendidikan, 5(1), 161-171. https://doi.org/10.21831/cp.v5i1.1269

Wijaksono, B., Hubeis, A. V., \& Saptono, I. T. (2017). Pengaruh Kualitas Kerja terhadap Kinerja Bank BNI Syariah Cabang Bogor. Jurnal Aplikasi Bisnis dan Manajemen. https://doi.org/10.17358/jabm.3.2.254

Yuliati, S. R., \& Lestari, I. (2018). Higher-Order Thinking Skills (HOTS) Analysis of Students In Solving HOTS Question in Higher Education. Perspektif Ilmu Pendidikan, 32(2), 181-188. https://doi.org/10.21009/pip.322.10

Zoller, U., \& Tsaparlis, G. (1997). Higher and Lower-Order Cognitive Skills: The Case of Chemistry. Research in Science Education, 27(1), 117-130. https://doi.org/10.1007/BF02463036

Zorluoğlu, S. L., Bağrıyanık, K. E., \& Şahintürk, A. (2019). Analyze of the Science and Technology Course TEOG Questions based on the Revised Bloom Taxonomy and their Relation between the Learning Outcomes of the Curriculum. International Journal of Progressive Education, 15(2), 104-117. https://doi.org/10.29329/ijpe.2019.189.8 